\title{
Prediabetes in Patients with Stroke or Transient Ischemic Attack: Prevalence, Risk and Clinical Management
}

\author{
Susanne Fonville ${ }^{a}$ Adrienne A.M. Zandbergen $^{b}$ Peter J. Koudstaal ${ }^{a}$ \\ Heleen M. den Hertog ${ }^{a, c}$ \\ aDepartment of Neurology, Erasmus Medical Center, and b Department of Internal Medicine, Ikazia Hospital, \\ Rotterdam, and ' Department of Neurology, Medisch Spectrum Twente, Enschede, The Netherlands
}

\section{Key Words}

Stroke $\cdot$ Transient ischemic attack · Prediabetes - Glucose metabolism

\begin{abstract}
Background: The prevalence of diabetes is emerging worldwide and is an important modifiable risk factor for stroke. People with prediabetes, an intermediate metabolic state between normal glucose metabolism and diabetes, have a tenfold increased risk of developing diabetes compared to those with a normal glucose metabolism. Prediabetes is comprised of impaired fasting glucose and/or impaired glucose tolerance and/or disturbed glycosylated hemoglobin levels. Prediabetes is highly prevalent in nondiabetic patients with transient ischemic attack (TIA) or ischemic stroke and nearly doubles their risk of stroke. This offers new options for secondary stroke prevention. Summary: Several detection methods exist for identifying (pre)diabetes, including fasting plasma glucose, 2-hour postload glucose and glycosylated hemoglobin levels. The concordance between these tests is not $100 \%$, and they seem to be complementary. Screening for (pre)diabetes after stroke with fasting plasma glucose levels alone is insufficient, and 2-hour postload glucose and/or glycosylated hemoglobin levels should
\end{abstract}

be determined as well. The prevalence of prediabetes in previously nondiabetic patients with a recent TIA or stroke ranges from 23 to $53 \%$. This high prevalence in the acute phase after stroke can be transient or persistent, representing undiagnosed abnormal glucose metabolism. Impaired fasting glucose and impaired glucose tolerance have different pathophysiological mechanisms, including hepatic insulin resistance and muscle insulin resistance, respectively. Prediabetes seems to be a modest predictor for stroke, but doubles the risk for recurrent stroke. The relation between prediabetes after stroke and functional outcome is still unknown. However, it is most likely that prediabetes is a risk factor for a poor clinical outcome after stroke. There is a growing recognition that patients with prediabetes should be treated more aggressively. Both lifestyle and pharmacological interventions are possible treatment strategies. They are at least equally effective in preventing progression to diabetes. Lifestyle changes are difficult to maintain over a long period. The evidence of pharmacological interventions on stroke or other cardiovascular diseases is limited though and is still subject of several clinical trials. Conclusions: As the prevalence of prediabetes is growing rapidly, prediabetes might become one of the most important modifiable therapeutic targets in both primary and secondary prevention.

(c) 2014 S. Karger AG, Basel

\section{KARGER}

E-Mail karger@karger.com

www.karger.com/ced (c) 2014 S. Karger AG, Basel

1015-9770/14/0376-0393\$39.50/0
Susanne Fonville, MD

Department of Neurology, Erasmus Medical Center

PO Box 2040

NL-3000 CA Rotterdam (The Netherlands)

E-Mail s.fonville@erasmusmc.nl 


\section{Introduction}

Type 2 diabetes mellitus is an increasing problem in the Western world and is accompanied by a reduced life expectancy. Prediabetes is an intermediate metabolic state between normal glucose metabolism and type 2 diabetes, representing a high risk of developing type 2 diabetes in the future $[1,2]$. Up to $70 \%$ of the patients with prediabetes may develop type 2 diabetes [1]. Prediabetes comprises impaired fasting glucose and/or impaired glucose tolerance and/or impaired glycosylated hemoglobin $[1,2]$. The risk of developing type 2 diabetes is approximately $0.7 \%$ per year in normoglycemic individuals, whereas patients with impaired fasting glucose or impaired glucose tolerance have a yearly risk of 5-10\% [1]. The transition from prediabetes to type 2 diabetes usually takes several years but may also be more rapid [1].

The estimated worldwide prevalence in 2010 of impaired glucose tolerance was $7.9 \%$. In Europe, the prevalence was even higher, $8.9 \%$. The prevalence of impaired fasting glucose is estimated at $5 \%$ but the use of 2 different criteria (from the American Diabetes Association and the World Health Organization) hampers the comparison of various studies [3].

Patients with prediabetes do not only have an increased risk of type 2 diabetes, but also of cardiovascular diseases, including stroke and recurrent stroke [4-6]. There is a growing recognition that patients with prediabetes should be treated more aggressively. Both lifestyle modification and antidiabetic drugs lower the risk of developing type 2 diabetes $[7,8]$. However, the effect of these treatments on preventing cardiovascular events is still the subject of several trials $[9,10]$.

This review provides an updated overview of prediabetes in patients with stroke or transient ischemic attack (TIA). We discuss methods of identification and the prevalence of prediabetes in stroke patients. We also explore the pathophysiology of prediabetes in stroke patients, the association with (recurrent) cardiovascular events, and the impact on functional outcome and therapeutic options.

\section{Identification of Prediabetes}

Several methods are known to identify people with prediabetes, including fasting plasma glucose levels, 2-hour postload glucose levels and glycosylated hemoglobin levels. The cutoff values for the different methods are shown in table 1 .
Table 1. Cutoff values of the different glucose tests according to the American Diabetes Association

\begin{tabular}{lllll}
\hline & $\begin{array}{l}\text { Normal } \\
\text { glucose } \\
\text { metabolism }\end{array}$ & $\begin{array}{l}\text { Pre- } \\
\text { diabetes }\end{array}$ & $\begin{array}{l}\text { Diabetes } \\
\text { mellitus }\end{array}$ \\
\hline Fasting plasma glucose, $\mathrm{mmol} / \mathrm{l}$ & $<5.6^{1}$ & $5.6-6.9^{1}$ & $\geq 7.0$ \\
Two-hour postload glucose, $\mathrm{mmol} / \mathrm{l}$ & $<7.8$ & $7.8-11.0$ & $\geq 11.1$ \\
Glycosylated hemoglobin, $\mathrm{mmol} / \mathrm{mol}$ & $<39$ & $39-47$ & $\geq 48$ \\
\hline
\end{tabular}

${ }^{1}$ According to the World Health Organization [1], <6.1 and 6.1 $-6.9 \mathrm{mmol} / \mathrm{l}$, respectively.

Fasting plasma glucose levels can be used to diagnose impaired fasting glucose. After overnight fasting (at least $8 \mathrm{~h}$ ), fasting plasma glucose levels are measured. The definition of impaired fasting glucose is however not clear. The American Diabetes Association reduced the lower cutoff point of the definition of impaired fasting glucose in 2003 to $5.6 \mathrm{mmol} / \mathrm{l}$, but the World Health Organization preserved the previous cutoff point of $6.1 \mathrm{mmol} / 1[1,2]$. Both definitions are used in stroke-related trials.

An oral glucose tolerance test can be performed to detect impaired glucose tolerance. After overnight fasting, a solution of $75 \mathrm{~g}$ glucose in $150 \mathrm{ml}$ water is ingested by the patient. Two hours after ingestion, the 2 -hour postload glucose levels are measured [11]. Unlike impaired fasting glucose, the American Diabetes Association and World Health Organization agree on the definition of impaired glucose tolerance $[1,2]$.

Glycosylated hemoglobin levels are mostly used as a marker of chronic hyperglycemia in the evaluation of known diabetic patients. The glucose levels of the previous 2-3 months are reflected in this marker. However, recently, the American Diabetes Association, the International Diabetes Federation and the European Association for the Study of Diabetes published a report in which the use of glycosylated hemoglobin levels was recommended for the diagnosis of (pre)diabetes [2]. The advantage of glycosylated hemoglobin levels over fasting plasma glucose and 2-hour postload glucose in identifying prediabetes in patients with a recent stroke is that it remains unaffected by the acute-phase reaction [2].

The concordance between these 3 tests is not $100 \%$ [12]. Furthermore, several studies showed that the use of fasting plasma glucose levels alone is insufficient to detect (pre)diabetes. Both 2-hour postload glucose and glycosylated hemoglobin levels diagnose patients with (pre)diabetes otherwise undetected [13-18]. 
Table 2. Overview of studies assessing the prevalence of prediabetes in stroke patients

\begin{tabular}{|c|c|c|c|c|c|c|c|c|}
\hline First author & Region & Event & $\begin{array}{l}\text { Glucose } \\
\text { assessment }\end{array}$ & $\begin{array}{l}\text { Time between } \\
\text { event and } \\
\text { glucose level } \\
\text { assessment }\end{array}$ & $\begin{array}{l}\text { Previously } \\
\text { nondiabetic } \\
\text { patients, } \mathrm{n}\end{array}$ & $\begin{array}{l}\text { Normal } \\
\text { glucose } \\
\text { metabo- } \\
\text { lism, n }\end{array}$ & $\begin{array}{l}\text { Pre- } \\
\text { diabetes, } \\
n\end{array}$ & $\begin{array}{l}\text { Newly } \\
\text { diagnosed } \\
\text { diabetes, } \\
\mathrm{n}\end{array}$ \\
\hline \multicolumn{9}{|c|}{ Glucose assessment in the acute phase ( $<3$ months after event) } \\
\hline Vancheri [23] & Europe & IS & OGTT & 7 days & 96 & $15(16)$ & $37(39)$ & $44(46)$ \\
\hline Matz [14] & Europe & $\mathrm{IS}+\mathrm{TIA}+\mathrm{ICH}$ & FPG + OGTT & $7-10$ days & 190 & $94(49)$ & $57(30)$ & $39(21)$ \\
\hline Urabe $[15]$ & Japan & IS & FPG + OGTT & $\geq 2$ weeks & 113 & $42(37)$ & $43(38)$ & $28(25)$ \\
\hline Dave [24] & South Africa & IS & FPG + OGTT & $2-3$ days & 107 & $42(39)$ & $39(36)$ & $26(24)$ \\
\hline Jia [20] & China & IS & FPG + OGTT & 14 days & 110 & $37(34)$ & $32(29)$ & $41(37)$ \\
\hline Jia [16] & China & IS & FPG + OGTT & 14 days & 1,793 & $706(39)$ & $556(31)$ & $531(30)$ \\
\hline Huisa [25] & USA & IS & $\mathrm{HbA}_{1 \mathrm{c}}$ & on admission & 166 & $53(32)$ & $88(53)$ & $25(15)$ \\
\hline Fonville [18] & Europe & IS + TIA + ICH & $\begin{array}{l}\text { FPG + OGTT } \\
+\mathrm{HbA}_{1 \mathrm{c}}\end{array}$ & $\begin{array}{l}4 \text { days } \\
\text { (IQR 3-11) }\end{array}$ & 700 & $147(21)$ & $365(52)$ & $188(27)$ \\
\hline Total & & & & & 3,275 & $1,136(35)$ & $1,217(37)$ & $922(28)$ \\
\hline \multicolumn{9}{|c|}{ Glucose assessment in the postacute phase ( $\geq 3$ months after event) } \\
\hline Lam [21] & China & IS & OGTT & $3-6$ months & 111 & $64(58)$ & $26(23)$ & $21(19)$ \\
\hline Gray [22] & Europe & $\mathrm{IS}+\mathrm{ICH}$ & OGTT & 12 weeks & 62 & $26(42)$ & $23(37)$ & $13(21)$ \\
\hline Kernan [13] & USA & IS + TIA & FPG + OGTT & $\begin{array}{l}105 \text { days } \\
\text { (range } 24-180 \text { ) }\end{array}$ & 98 & $44(45)$ & $30(31)$ & $24(24)$ \\
\hline Vancheri [23] & Europe & IS & OGTT & 3 months & 96 & $34(35)$ & $26(27)$ & $36(38)$ \\
\hline Ivey [19] & USA & IS & FPG + OGTT & $>6$ months & 80 & $30(38)$ & $37(46)$ & $13(16)$ \\
\hline Dave [24] & South Africa & IS & FPG + OGTT & 3 months & 44 & $26(59)$ & $12(27)$ & $6(14)$ \\
\hline Jia [20] & China & IS & FPG + OGTT & 3 months & 107 & $42(39)$ & $37(35)$ & $28(26)$ \\
\hline Total & & & & & 598 & $266(44)$ & $191(32)$ & $141(24)$ \\
\hline
\end{tabular}

Figures in parentheses indicate percentages. IS = Ischemic stroke; ICH = intracerebral hemorrhage; OGTT = oral glucose tolerance test; $\mathrm{FPG}=$ fasting plasma glucose; $\mathrm{HbA}_{1 \mathrm{c}}=$ glycosylated hemoglobin.

\section{Prevalence of Prediabetes in Patients with Stroke}

The prevalence of prediabetes in previously nondiabetic patients with a recent ischemic stroke or TIA is on average $37 \%$ (range $29-53 \%$ ) in the acute phase (within 3 months after the event) and 32\% (range 23-46\%) in the postacute phase ( $\geq 3$ months after the event), which is clearly higher than in the overall population [13-16, 1825]. Several studies assessed the prevalence of prediabetes based on fasting plasma glucose levels and/or 2-hour postload glucose levels in stroke patients [13-16, 19-24], 1 study assessed the prevalence based on glycosylated hemoglobin levels [25] and only 1 study assessed the prevalence based on all three detection methods [18]. However, inclusion criteria, definition of disturbed glucose metabolism, ethnicity and time between event and glucose measurement differed among these studies, making it difficult to compare them (table 2).
Most studies were performed in patients with ischemic stroke $[15,16,19-21,23-25]$. Others did not differentiate between patients with ischemic stroke, intracerebral hemorrhage or a TIA $[13,14,22]$. Studies were performed in different regions of the world including China $[16,20$, 21], Japan [15], South Africa [24], the USA [13, 19, 25] and Europe [14, 18, 22, 23]. The prevalence of diabetes, and also of prediabetes, is influenced by ethnicity [26], and this factor should therefore be taken into account when considering the prevalence of prediabetes in stroke patients. Time from the event to glucose level assessment also differed between the studies. Some assessed glucose levels in the acute phase ( $<2$ weeks after the event) [14-16, $18,20,23-25]$, others in the chronic stroke phase $(>3$ months after the event) $[13,19,21,22]$. Only 3 studies repeated the glucose measurement after 3 months, and this revealed that $22-44 \%$ of the patients had persistent prediabetes $[20,23,24]$. No predictors for persistent prediabetes are known. 


\section{Pathophysiology of Prediabetes after Stroke}

\section{Pathophysiology of Hyperglycemia in Acute Ischemic}

Stroke

Hyperglycemia is often present in patients with stroke. Up to $40 \%$ of these patients have no history of diabetes [27, 28]. This hyperglycemia can be transient, or persistent, reflecting an undiagnosed abnormal glucose metabolism $[29,30]$. Serious illness, like stroke, can result in an acute stress reaction that involves stimulation of the hypothalamus-pituitary-adrenal axis resulting in a release of catecholamines, cortisol and glucagon. This release results in insulin resistance, glycogenolysis, gluconeogenesis, proteolysis and lipolysis [29, 30]. Furthermore, there is substantial evidence that stroke can induce hyperglycemia indirectly by activation of an inflammatory reaction [29-31].

\section{Pathophysiology of Prediabetes}

Impaired fasting glucose and impaired glucose tolerance do not share the same pathophysiological mechanisms. In individuals with a normal glucose metabolism, ingested glucose uptake occurs in insulin-insensitive tissues, like brain and erythrocytes. The endogenous glucose production takes primarily place in the liver. Uptake and production of glucose are complementary: fasting plasma glucose levels are mainly dependent on glucose production, which is regulated by the plasma insulin and glucagon concentrations. After glucose ingestion, insulin secretion is promoted by the increased plasma glucose levels. Subsequently, glucose production is suppressed and glucose uptake, primarily by muscle, is stimulated, to remain normoglycemic [26].

Impaired fasting glucose reflects hepatic insulin resistance and normal muscle insulin sensitivity. On the other hand, patients with impaired glucose tolerance have (near) normal hepatic insulin sensitivity but display muscle insulin resistance. Insulin secretion is impaired in both impaired fasting glucose and impaired glucose tolerance, but in different ways. Patients with impaired fasting glucose have a decreased early-phase insulin response to oral glucose whereas patients with impaired glucose tolerance have deficiencies in both early- and late-phase insulin responses. Patients with both impaired fasting glucose and impaired glucose tolerance show both hepatic and muscle insulin resistance and decreased both earlyand late-phase insulin responses to oral glucose, which might explain the higher risk in these patients to develop diabetes compared with patients with impaired fasting glucose or impaired glucose tolerance alone [26, 32]. There is evidence that insulin sensitivity is impaired after ischemic stroke, possibly due to decreased hepatic insulin receptor expression and upregulation of gluconeogenesis, which can lead to impaired glucose tolerance [31].

Patients with impaired fasting glucose or impaired glucose tolerance and glucose levels in the higher range have an increased risk compared with patients with glucose levels in the lower range. This indicates that prediabetes should not be considered as a distinct clinical entity, but rather that glucose levels should be regarded as a continuum with increasing levels representing an increasing risk of developing diabetes.

\section{Association between Prediabetes and (Recurrent) Stroke}

Prediabetes is considered a risk factor for developing (recurrent) ischemic stroke. Several studies have shown the association between both fasting plasma glucose and 2-hour postload glucose levels on the one hand and risk of cardiovascular disease or ischemic stroke on the other. Most studies indicate that 2-hour postload glucose levels are a stronger predictor of stroke than fasting plasma glucose levels [33-36].

Recently, two meta-analyses assessed the association between prediabetes and cardiovascular disease and stroke, respectively $[4,5]$. The effects of impaired fasting glucose and/or impaired glucose tolerance on cardiovascular or stroke risk were modest. However, the changing definitions of impaired fasting glucose and different statistical assessments (hazard ratio, HR, vs. relative risk vs. odds ratio) over the years make it difficult to compare the results of the studies used in these meta-analyses.

Few studies have investigated the risk of recurrent stroke. Vermeer et al. [6] assessed the association between random plasma glucose levels and recurrent stroke in patients with a TIA or minor ischemic stroke in the previous 3 months. Patients with nonfasting glucose levels in the range of impaired glucose tolerance had a nearly twofold increased risk of recurrent stroke compared to those with normal glucose levels (adjusted HR 1.8, 95\% confidence interval, CI, 1.1-3.0). Patients with nonfasting glucose levels in the diabetes range (11.1 mmol/l or higher) had nearly a threefold increased risk (adjusted HR 2.8, 95\% CI 1.9-4.1). However, no associations were found between glucose levels and risk of myocardial infarction or cardiac death [6].

Several studies have assessed the risk of recurrent cardiovascular events in patients with prediabetes and a myocardial infarction, and have shown an increased risk of re- 
current cardiovascular disease with adjusted HRs ranging from 2.2 to 4.2 [37, 38]. Also 2-hour postload glucose levels predict cardiovascular events in patients with myocardial infarction without known pre-existent diabetes [39]. However, they did not differentiate between myocardial infarction and ischemic stroke in outcome assessment.

\section{Influence on Outcome after Stroke}

Diabetes is associated with an unfavorable functional outcome and slightly increased case fatality after stroke [40]. The effect of poststroke hyperglycemia or stress hyperglycemia on functional outcome after stroke in nondiabetic patients has been a subject of many studies [27, 28]. Acute hyperglycemia in both diabetic and nondiabetic patients is not only associated with mortality, but also with unfavorable functional outcome (modified Rankin Scale $\geq 2$ [41]) at 3 months after the event. The pooled relative risk for in-hospital or 30-day mortality is 3.07 (95\% CI 2.50-3.79), and for poor functional outcome it is 1.41 (95\% CI 1.16-1.73) in nondiabetic patients with stress hyperglycemia [27]. Different cutoff points are used to define hyperglycemia in these studies, ranging from 6.0 to $8.0 \mathrm{mmol} / \mathrm{l}$ [27]. However, glucose level as a continuous variable is associated with functional outcome as well [42]. Also the functional outcome after treatment with intravenous tissue-type plasminogen activator is influenced by hyperglycemia and the presence of diabetes [43-45].

However, all these studies have studied the relationship between glucose levels on admission or random glucose levels rather than the fasting plasma glucose and/or 2-hour postload glucose and/or glycosylated hemoglobin levels with outcome. Only 1 recent study has assessed the association between prediabetes and functional outcome after 30 days, with an adjusted odds ratio for poor functional outcome (modified Rankin Scale score 2-6) of 1.9 (95\% CI 0.8-5.0) [46]. Nevertheless, it is most likely, but still unproven, that patients with prediabetes have a risk of poor functional outcome somewhere between the risk of patients with normal glucose metabolism and of patients with diabetes.

\section{Treatment Strategies}

The prevention of type 2 diabetes in prediabetic patients has been the subject of many large randomized clinical trials. Both nonpharmacological and pharmacological interventions are possible treatment strategies.

Prediabetes in Patients with Stroke or TIA

\section{Nonpharmacological Interventions}

Nonpharmacological interventions comprise lifestyle intervention. Extending lifestyle advice by means of individualized diet and regular exercise with intensive counseling sessions clearly reduces the progression to type 2 diabetes by $33-58 \%$ compared to those receiving standard lifestyle advice [7, 47-49]. One study compared lifestyle intervention with metformin treatment. The incidence of new-onset type 2 diabetes was reduced by $58 \%$ (95\% CI 48-66, $\mathrm{p}<0.001)$ in patients receiving lifestyle intervention and $31 \%(95 \%$ CI $17-43, \mathrm{p}<0.001)$ in patients randomized to metformin compared with patients with placebo. The incidence of type 2 diabetes was also significantly lower in the lifestyle intervention group compared with the metformin group $(\mathrm{p}<0.001)$ [7]. However, no significant effect of lifestyle intervention on cardiovascular disease was found [50-52].

\section{Pharmacological Interventions}

Different classes of antidiabetic drugs to prevent progression to type 2 diabetes in patients with prediabetes have been studied in randomized clinical trials. Biguanides (metformin) [7, 52-54], a-glucosidase inhibitors (acarbose) $[55,56]$ and glitazones (rosiglitazone and pioglitazone) $[53,57,58]$ all significantly decrease the risk of type 2 diabetes, with HRs ranging from 0.31 to 0.75 .

Not only antidiabetic drugs, but also inhibitors of the renin-angiotensin system have been studied for their effects on glucose homeostasis $[59,60]$. For example, the angiotensin receptor antagonist valsartan reduced the risk for type 2 diabetes (HR 0.38, 95\% CI 0.33-0.44) [59].

Intensive glycemic control is important to reduce the risk of microvascular and neuropathic complications in patients with diabetes mellitus. However, there are few data supporting the benefits of intensive glycemic control in reducing the risk of cardiovascular events in diabetic patients with previous cardiovascular disease, including stroke [61-63]. It is suggested that patients with a shorter duration of diabetes or lower glycosylated hemoglobin levels at entry might benefit from this intensive glucose control [63]. Therefore, we think that prediabetes is a more interesting starting point to initiate treatment than advanced diabetes mellitus.

The few studies on the effects of glucose-lowering pharmacological interventions on cardiovascular events in patients with prediabetes are not conclusive $[9,10]$, but a recent meta-analysis suggests that any intervention (either nonpharmacological and/or pharmacological) reduces the risk for fatal and nonfatal stroke (HR 0.76, 95\% CI 0.58-0.99) compared to no intervention [9]. 
Few studies have investigated the effect of pharmacological treatment in prediabetic patients with TIA or stroke. However, pioglitazone seemed to improve insulin sensitivity in nondiabetic patients with impaired insulin sensitivity [58], and treatment with metformin improved glucose tolerance in prediabetic patients with recent TIA or stroke [54]. No randomized clinical trials have been published on the effect of nonpharmacological and pharmacological interventions on the risk of recurrent stroke. The ongoing Metformin and sitAgliptin in patients with impAired glucose tolerance and a recent TIA or minor ischemic Stroke (MAAS) trial (http://www.trialregister. $\mathrm{nl} /$ trialreg/admin/rctview.asp? TC $=3196$ ) is a phase II trial investigating the feasibility and safety of both metformin and sitagliptin in patients with impaired glucose tolerance after TIA or ischemic stroke in preparation of a phase III trial to investigate the effect on the incidence of recurrent stroke. Furthermore, the Insulin Resistance Intervention after Stroke (IRIS) trial (http://clinicaltrials. gov/ct2/show/NCT00091949) is an ongoing phase III trial on the effect of treatment with thiazolidinedione drugs on recurrent stroke in patients with a recent TIA or ischemic stroke and insulin resistance.

The current guidelines for the prevention of recurrent stroke recommend treating patients with diabetes mellitus according to the existing guidelines of the American Diabetes Association [62], and not with intensive glycemic control [61]. Unfortunately, detection and detection methods of newly diagnosed diabetes mellitus and prediabetes, and the treatment of prediabetes are not mentioned in the current guidelines.

In conclusion, lifestyle intervention in patients with prediabetes seems to be at least an equally effective treatment strategy in preventing type 2 diabetes $[7,8]$ as drug therapy. It remains difficult to maintain lifestyle changes over a longer period, and they are a challenge for each patient. Therefore, pharmacological interventions might be a good supplement to these lifestyle interventions in preventing diabetes [64]. Furthermore, prediabetes seems to be more interesting than advanced diabetes to start treatment to prevent recurrent stroke.

\section{Conclusions}

Up to $53 \%$ of the nondiabetic patients with a recent ischemic stroke or TIA have prediabetes, which is clearly more than in the community.

Different screening methods are available. To detect all patients with an increased risk for diabetes and recurrent stroke, it is advisable to assess 2-hour postload glucose and glycosylated hemoglobin levels besides fasting plasma glucose levels. However, as more than $50 \%$ of the patients will return to a normal glucose metabolism within 3 months after the stroke, it is necessary to repeat the test in order to identify the patients with the highest risk of developing both diabetes and recurrent strokes.

Prediabetes increases the risk of cardiovascular disease and recurrent ischemic stroke, making this an important target for both primary and secondary prevention. Future studies should show whether prediabetes also affects functional outcome after stroke. Lifestyle interventions are at least equally effective as pharmacological interventions in preventing progression to type 2 diabetes but are more difficult to carry out. The effect of these interventions on the risk of (recurrent) cardiovascular disease is still unclear, but they are more promising than these interventions in patients with advanced diabetes.

As the prevalence of prediabetes is growing rapidly, prediabetes might become one of the most important modifiable therapeutic targets in both primary and secondary prevention. We therefore recommend that the routine screening of newly diagnosed diabetes mellitus and prediabetes with fasting plasma glucose, 2-hour postload glucose and glycosylaterd hemoglobin levels, and the treatment of prediabetes should be included into the future updating of the guidelines for the prevention of recurrent stroke.

\section{Disclosure Statement}

The authors declare that they have no conflict of interest.

\section{References}

1 Buysschaert M, Bergman M: Definition of prediabetes. Med Clin North Am 2011;95: 289-297, vii.

-2 American Diabetes Association: Diagnosis and classification of diabetes mellitus. Diabetes Care 2013;36(suppl 1):S67-S74.

- 3 Colagiuri S: Epidemiology of prediabetes. Med Clin North Am 2011;95:299-307, vii.
4 Ford ES, Zhao G, Li C: Pre-diabetes and the risk for cardiovascular disease: a systematic review of the evidence. J Am Coll Cardiol 2010;55:1310-1317.

5 Lee M, Saver JL, Hong KS, Song S, Chang KH, Ovbiagele B: Effect of pre-diabetes on future risk of stroke: meta-analysis. BMJ 2012; 344:e3564. 
6 Vermeer SE, Sandee W, Algra A, Koudstaal PJ, Kappelle LJ, Dippel DW: Impaired glucose tolerance increases stroke risk in nondiabetic patients with transient ischemic attack or minor ischemic stroke. Stroke 2006;37:14131417.

7 Knowler WC, Barrett-Connor E, Fowler SE, Hamman RF, Lachin JM, Walker EA, Nathan DM; Diabetes Prevention Program Research Group: Reduction in the incidence of type 2 diabetes with lifestyle intervention or metformin. N Engl J Med 2002;346:393-403.

8 Gillies CL, Abrams KR, Lambert PC, Cooper NJ, Sutton AJ, Hsu RT, Khunti K: Pharmacological and lifestyle interventions to prevent or delay type 2 diabetes in people with impaired glucose tolerance: systematic review and meta-analysis. BMJ 2007;334:299.

-9 Hopper I, Billah B, Skiba M, Krum H: Prevention of diabetes and reduction in major cardiovascular events in studies of subjects with prediabetes: meta-analysis of randomised controlled clinical trials. Eur J Cardiovasc Prev Rehabil 2011;18:813-823.

10 Califf RM, Boolell M, Haffner SM, Bethel MA, McMurray J, Duggal A, Holman RR: Prevention of diabetes and cardiovascular disease in patients with impaired glucose tolerance: rationale and design of the Nateglinide and Valsartan in Impaired Glucose Tolerance Outcomes Research (NAVIGATOR) trial. Am Heart J 2008;156:623-632.

11 WHO: Definition, diagnosis and classification of diabetes mellitus and its complications: report of a WHO consultation. Geneva, World Health Organization, 1999.

-12 American Diabetes Association: Standards of medical care in diabetes - 2012. Diabetes Care 2012;35(suppl 1):S11-S63.

-13 Kernan WN, Viscoli CM, Inzucchi SE, Brass LM, Bravata DM, Shulman GI, McVeety JC: Prevalence of abnormal glucose tolerance following a transient ischemic attack or ischemic stroke. Arch Intern Med 2005;165:227-233.

14 Matz K, Keresztes K, Tatschl C, Nowotny M, Dachenhausen A, Brainin M, Tuomilehto J: Disorders of glucose metabolism in acute stroke patients: an underrecognized problem. Diabetes Care 2006;29:792-797.

15 Urabe T, Watada H, Okuma Y, Tanaka R, Ueno Y, Miyamoto N, Tanaka Y, Hattori N, Kawamori R: Prevalence of abnormal glucose metabolism and insulin resistance among subtypes of ischemic stroke in Japanese patients. Stroke 2009;40:1289-1295.

-16 Jia Q, Zheng H, Zhao X, Wang C, Liu G, Wang Y, Liu L, Li H, Zhong L: Abnormal glucose regulation in patients with acute stroke across China: prevalence and baseline patient characteristics. Stroke 2012;43:650-657.

-17 Lindsberg PJ, Tuomi T, Kaste M: Oral glucose tolerance test should be performed after stroke and transient ischemic attack. Int J Stroke 2011;6:317-320.
18 Fonville S, Zandbergen AA, Vermeer SE, Dippel DW, Koudstaal PJ, den Hertog HM: Prevalence of prediabetes and newly diagnosed diabetes in patients with a transient ischemic attack or stroke. Cerebrovasc Dis 2013;36: 283-289.

19 Ivey FM, Ryan AS, Hafer-Macko CE, Garrity BM, Sorkin JD, Goldberg AP, Macko RF: High prevalence of abnormal glucose metabolism and poor sensitivity of fasting plasma glucose in the chronic phase of stroke. Cerebrovasc Dis 2006;22:368-371.

20 Jia Q, Zheng H, Liu L, Zhao X, Wang C, Jing J, Liang D, Wang Y, Zhou Y, Dong K, Yang Z, Wang Y: Persistence and predictors of abnormal glucose metabolisms in patients after acute stroke. Neurol Res 2010;32:359-365.

21 Lam KS, Ma JT, Woo E, Lam C, Yu YL: High prevalence of undiagnosed diabetes among Chinese patients with ischaemic stroke. Diabetes Res Clin Pract 1991;14:133-137.

22 Gray CS, Scott JF, French JM, Alberti KG, O'Connell JE: Prevalence and prediction of unrecognised diabetes mellitus and impaired glucose tolerance following acute stroke. Age Ageing 2004;33:71-77.

23 Vancheri F, Curcio M, Burgio A, Salvaggio S, Gruttadauria G, Lunetta MC, Dovico R, Alletto M: Impaired glucose metabolism in patients with acute stroke and no previous diagnosis of diabetes mellitus. Q J Med 2005;98: 871-878.

24 Dave JA, Engel ME, Freercks R, Peter J, May W, Badri M, Van Niekerk L, Levitt NS: Abnormal glucose metabolism in non-diabetic patients presenting with an acute stroke: prospective study and systematic review. Q J Med 2010;103:495-503.

25 Huisa BN, Roy G, Kawano J, Schrader R: Glycosylated hemoglobin for diagnosis of prediabetes in acute ischemic stroke patients. J Stroke Cerebrovasc Dis 2013;22:e564-e567.

26 Abdul-Ghani MA, Tripathy D, DeFronzo RA: Contributions of beta-cell dysfunction and insulin resistance to the pathogenesis of impaired glucose tolerance and impaired fasting glucose. Diabetes Care 2006;29:1130-1139.

27 Capes SE, Hunt D, Malmberg K, Pathak P, Gerstein HC: Stress hyperglycemia and prognosis of stroke in nondiabetic and diabetic patients: a systematic overview. Stroke 2001;32: 2426-2432.

28 Piironen K, Putaala J, Rosso C, Samson Y: Glucose and acute stroke: evidence for an interlude. Stroke 2012;43:898-902.

29 Dungan KM, Braithwaite SS, Preiser JC: Stress hyperglycaemia. Lancet 2009;373: 1798-1807.

30 Kruyt ND, Biessels GJ, Devries JH, Roos YB: Hyperglycemia in acute ischemic stroke: pathophysiology and clinical management. Nat Rev Neurol 2010;6:145-155.

31 Harada S, Fujita-Hamabe W, Tokuyama S: Ischemic stroke and glucose intolerance: a review of the evidence and exploration of novel therapeutic targets. J Pharmacol Sci 2012;118: $1-13$.
32 Nathan DM, Davidson MB, DeFronzo RA, Heine RJ, Henry RR, Pratley R, Zinman B; American Diabetes Association: Impaired fasting glucose and impaired glucose tolerance: implications for care. Diabetes Care 2007;30:753-759.

33 Qiao Q, Pyorala K, Pyorala M, Nissinen A, Lindstrom J, Tilvis R, Tuomilehto J: Twohour glucose is a better risk predictor for incident coronary heart disease and cardiovascular mortality than fasting glucose. Eur Heart J 2002;23:1267-1275.

34 DECODE Study Group: Glucose tolerance and cardiovascular mortality: comparison of fasting and 2-hour diagnostic criteria. Arch Intern Med 2001;161:397-405.

-35 Coutinho M, Gerstein HC, Wang Y, Yusuf S: The relationship between glucose and incident cardiovascular events. A metaregression analysis of published data from 20 studies of 95,783 individuals followed for 12.4 years. Diabetes Care 1999;22:233-240.

36 Qureshi AI, Giles WH, Croft JB: Impaired glucose tolerance and the likelihood of nonfatal stroke and myocardial infarction: the third national health and nutrition examination survey. Stroke 1998;29:1329-1332.

37 Donahue RP, Dorn JM, Stranges S, Swanson M, Hovey K, Trevisan M: Impaired fasting glucose and recurrent cardiovascular disease among survivors of a first acute myocardial infarction: evidence of a sex difference? The western New York experience. Nutr Metab Cardiovasc Dis 2011;21:504-511.

38 Bartnik M, Malmberg K, Norhammar A, Tenerz A, Ohrvik J, Ryden L: Newly detected abnormal glucose tolerance: an important predictor of long-term outcome after myocardial infarction. Eur Heart J 2004;25:1990-1997.

-39 Henareh L, Agewall S: 2-h postchallenge plasma glucose predicts cardiovascular events in patients with myocardial infarction without known diabetes mellitus. Cardiovasc Diabetol 2012;11:93.

40 Luitse MJ, Biessels GJ, Rutten GE, Kappelle LJ: Diabetes, hyperglycaemia, and acute ischaemic stroke. Lancet Neurol 2012;11:261271.

41 Van Swieten JC, Koudstaal PJ, Visser MC, Schouten HJ, van Gijn J: Interobserver agreement for the assessment of handicap in stroke patients. Stroke 1988;19:604-607.

42 Diener HC, Lees KR, Lyden P, Grotta J, Davalos A, Davis SM, Shuaib A, Ashwood T, Wasiewski W, Alderfer V, Hardemark HG, Rodichok L: NXY-059 for the treatment of acute stroke: pooled analysis of the SAINT I and II trials. Stroke 2008;39:1751-1758.

43 Poppe AY, Majumdar SR, Jeerakathil T, Ghali W, Buchan AM, Hill MD: Admission hyperglycemia predicts a worse outcome in stroke patients treated with intravenous thrombolysis. Diabetes Care 2009;32:617622 . 
-44 De Silva DA, Ebinger M, Christensen S, Parsons MW, Levi C, Butcher K, Barber PA, Bladin C, Donnan GA, Davis SM: Baseline diabetic status and admission blood glucose were poor prognostic factors in the EPITHET trial. Cerebrovasc Dis 2010;29:14-21.

-45 Putaala J, Sairanen T, Meretoja A, Lindsberg PJ, Tiainen M, Liebkind R, Strbian D, Atula S, Artto V, Rantanen K, Silvonen P, Piironen K, Curtze S, Happola O, Mustanoja S, Pitkaniemi J, Salonen O, Silvennoinen H, Soinne L, Kuisma M, Tatlisumak T, Kaste M: Postthrombolytic hyperglycemia and 3-month outcome in acute ischemic stroke. Cerebrovasc $D$ is 2011;31:83-92.

-46 Tanaka R, Ueno Y, Miyamoto N, Yamashiro K, Tanaka Y, Shimura H, Hattori N, Urabe T: Impact of diabetes and prediabetes on the short-term prognosis in patients with acute ischemic stroke. J Neurol Sci 2013;332:45-50.

47 Pan XR, Li GW, Hu YH, Wang JX, Yang WY, An ZX, Hu ZX, Lin J, Xiao JZ, Cao HB, Liu PA, Jiang XG, Jiang YY, Wang JP, Zheng $H$, Zhang H, Bennett PH, Howard BV: Effects of diet and exercise in preventing NIDDM in people with impaired glucose tolerance. The Da Qing IGT and Diabetes Study. Diabetes Care 1997;20:537-544.

48 Tuomilehto J, Lindstrom J, Eriksson JG, Valle TT, Hamalainen H, Ilanne-Parikka P, Keinanen-Kiukaanniemi S, Laakso M, Louheranta A, Rastas M, Salminen V, Uusitupa M: Prevention of type 2 diabetes mellitus by changes in lifestyle among subjects with impaired glucose tolerance. N Engl J Med 2001; 344:1343-1350.

49 Eriksson KF, Lindgarde F: Prevention of type 2 (non-insulin-dependent) diabetes mellitus by diet and physical exercise. The 6-year Malmo Feasibility Study. Diabetologia 1991;34: 891-898.

50 Li G, Zhang P, Wang J, Gregg EW, Yang W, Gong Q, Li H, Jiang Y, An Y, Shuai Y, Zhang B, Zhang J, Thompson TJ, Gerzoff RB, Roglic G, Hu Y, Bennett PH: The long-term effect of lifestyle interventions to prevent diabetes in the China Da Qing Diabetes Prevention Study: a 20-year follow-up study. Lancet 2008; 371:1783-1789.
1 Uusitupa M, Peltonen M, Lindstrom J, Aunola S, Ilanne-Parikka P, Keinanen-Kiukaanniemi S, Valle TT, Eriksson JG, Tuomilehto J: Ten-year mortality and cardiovascular morbidity in the Finnish diabetes prevention study - secondary analysis of the randomized trial. PLoS One 2009;4:e5656.

52 Ratner R, Goldberg R, Haffner S, Marcovina S, Orchard T, Fowler S, Temprosa M: Impact of intensive lifestyle and metformin therapy on cardiovascular disease risk factors in the diabetes prevention program. Diabetes Care 2005;28:888-894.

53 Zinman B, Harris SB, Neuman J, Gerstein HC, Retnakaran RR, Raboud J, Qi Y, Hanley AJ: Low-dose combination therapy with rosiglitazone and metformin to prevent type 2 diabetes mellitus (CANOE trial): a doubleblind randomised controlled study. Lancet 2010;376:103-111.

54 Den Hertog HM, Vermeer SE, Zandbergen AA, Achterberg S, Dippel DW, Algra A, Kappelle LJ, Koudstaal PJ: Safety and feasibility of metformin in patients with impaired glucose tolerance and a recent TIA or minor ischemic stroke (LIMIT) trial - a multicenter, randomized, open-label phase II trial. Int J Stroke, Epub ahead of print.

55 Chiasson JL, Josse RG, Gomis R, Hanefeld M, Karasik A, Laakso M: Acarbose treatment and the risk of cardiovascular disease and hypertension in patients with impaired glucose tolerance: The stop-NIDDM trial. JAMA 2003; 290:486-494.

56 Chiasson JL: Acarbose for the prevention of diabetes, hypertension, and cardiovascular disease in subjects with impaired glucose tolerance: the study to prevent non-insulin-dependent diabetes mellitus (stop-NIDDM) trial. Endocr Pract 2006;12(suppl 1):25-30.
57 Gerstein HC, Yusuf S, Bosch J, Pogue J, Sheridan P, Dinccag N, Hanefeld M, Hoogwerf B, Laakso M, Mohan V, Shaw J, Zinman B, Holman RR: Effect of rosiglitazone on the frequency of diabetes in patients with impaired glucose tolerance or impaired fasting glucose: a randomised controlled trial. Lancet 2006; 368:1096-1105.

58 Kernan WN, Inzucchi SE, Viscoli CM, Brass LM, Bravata DM, Shulman GI, McVeety JC, Horwitz RI: Pioglitazone improves insulin sensitivity among nondiabetic patients with a recent transient ischemic attack or ischemic stroke. Stroke 2003;34:1431-1436.

59 McMurray JJ, Holman RR, Haffner SM, et al: Effect of valsartan on the incidence of diabetes and cardiovascular events. N Engl J Med 2010; 362:1477-1490.

60 Saxena R, Wijnhoud AD, Koudstaal PJ, van den Meiracker AH: Induced elevation of blood pressure in the acute phase of ischemic stroke in humans. Stroke 2000;31:546-548.

-61 Furie KL, Kasner SE, Adams RJ, Albers GW, Bush RL, Fagan SC, Halperin JL, Johnston SC, Katzan I, Kernan WN, Mitchell PH, Ovbiagele B, Palesch YY, Sacco RL, Schwamm LH, Wassertheil-Smoller S, Turan TN, Wentworth D: Guidelines for the prevention of stroke in patients with stroke or transient ischemic attack: a guideline for healthcare professionals from the American Heart Association/American Stroke Association. Stroke 2011;42:227-276.

62 American Diabetes Association: Standards of medical care in diabetes - 2013. Diabetes Care 2013;36(suppl 1):S11-S66.

63 Skyler JS, Bergenstal R, Bonow RO, Buse J, Deedwania P, Gale EA, Howard BV, Kirkman MS, Kosiborod M, Reaven P, Sherwin RS: Intensive glycemic control and the prevention of cardiovascular events: implications of the ACCORD, ADVANCE, and VA diabetes trials: a position statement of the American Diabetes Association and a scientific statement of the American College of Cardiology Foundation and the American Heart Association. Diabetes Care 2009;32:187-192.

64 Chiasson JL: Prevention of type 2 diabetes: fact or fiction? Expert Opin Pharmacother 2007;8:3147-3158. 